\title{
The role of apoptosis in the pathogenesis and treatment of diseases
}

\author{
E. Solary, L. Dubrez, B. Eymin
}

The role of apoptosis in the pathogenesis and treatment of diseases. E. Solary, L. Dubrez, B. Eymin. CERS Journals Ltd 1996.

ABSTRACT: In adult multicellular organisms, homeostasis is determined in each cell lineage by a balance between cell death and cell growth. Dysregulation of cell death mechanisms is involved in the pathogenesis of an increasing number of diseases. Defective apoptosis can participate in malignant transformation, viral latency and autoimmune diseases. Excessive apoptotic cell death is involved in CD4+ T-cell depletion observed in acquired immune deficiency syndrome, in fulminant hepatitis associated with infection by hepatitis $B$ and $C$ viruses, in some neurodegenerative disorders and haematological diseases, in polycystic kidney disease and ischaemia.

Three steps can be distinguished in the pathway that leads to cell death. The first step involves interactions between the extracellular and intracellular signals that decide whether a cell should live or die. When death is chosen, a common pathway that involves at least the Bcl-2- family of proteins and the interleukin-1 $\beta$ (IL-1 $\beta$ )converting enzyme-related cysteine proteases confirms whether or not the cell should die. Finally, if death is allowed to occur, the apoptotic process itself is characterized by deoxyribonucleic acid (DNA) fragmentation, proteolysis and morphological changes that precede the engulfment of apoptotic cells by neighbouring cells and phagocytes.

Several inducers and inhibitors of apoptosis acting on one or several of these three steps that characterize the apoptotic process have been identified in vitro. Their potential usefulness in improving the current therapeutic strategies and designing new strategies in several different diseases is discussed. Eur Respir J., 1996, 9, 1293-1305

Laboratory of Oncohematology and Pharmacology, Faculty of Medicine, Dijon, France.

Correspondence: E. Solary

Laboratory of Oncohematology and Pharmacology

Faculty of Medicine

7 boulevard Jeanne d'Arc

21033 Dijon Cedex

France

Keywords: Apoptosis

diseases

pathogenesis

treatment

Received: October 51995

Accepted after revision February 81996
In a famous French play by Molière, the prominent character, Monsieur Jourdain, realizes that he has been speaking in prose for a long time without even knowing it. Similarly, the recent interest in cell death mechanisms has revealed that we have been using induction or inhibition of apoptosis for a long time for the treatment of some diseases without knowing it. For instance, chemotherapeutic drugs and radiations induce apoptosis of tumour cells [1] and haematopoietic growth factors act by preventing apoptosis of haematopoietic progenitors [2]. A better understanding of the mechanisms that regulate cell death pathways might make it possible to improve the current therapeutic strategies and to define new strategies in several different diseases.

\section{To live or to die?}

In adult multicellular organisms, different cell types vary widely in the mechanisms by which they maintain themselves throughout life. Red blood cells undergo constant renewal from haematopoietic progenitor cells, whereas neural cells have no or limited capacity for self-renewal. Between these extremes, lymphocytes and cells from reproductive organs undergo cyclical expansions and contractions as they participate in host defence and reproduction, respectively. Within all of these cell lineages, the control of cell number is determined by a balance between cell proliferation and cell death. Recent studies suggest that the mechanisms that control cell proliferation and cell death could share several factors. Growth factors can either stimulate cell growth or prevent cell death [2-4]. Antigenic stimulation of the T-cell receptor first triggers the proliferation of mature peripheral T-cells, which are later eliminated by Fas-mediated apoptosis [5]. Protooncogenes associated with cell proliferation, such as $c$ $m y c$, are capable of inducing apoptosis when they are aberrantly expressed [6]. Tumour suppressor genes, such as $p 53$, are involved into checkpoints that decide whether a cell progresses in cell cycle or dies by apoptosis in response to deoxyribonucleic acid (DNA) damage [7]. Therefore, a given signal will induce a cell either to live or to die, depending on the cell type and its level of differentiation [8]. Cell survival could depend upon the constant supply of survival factors provided by neighbouring cells and extracellular matrix [9-11].

\section{To die or not to die?}

Beyond different signalling pathways that ultimately converge to activate a cell death signal, apoptosis appears to involve a common final pathway that has been, at least partially, conserved throughout animal evolution (fig. 1). 


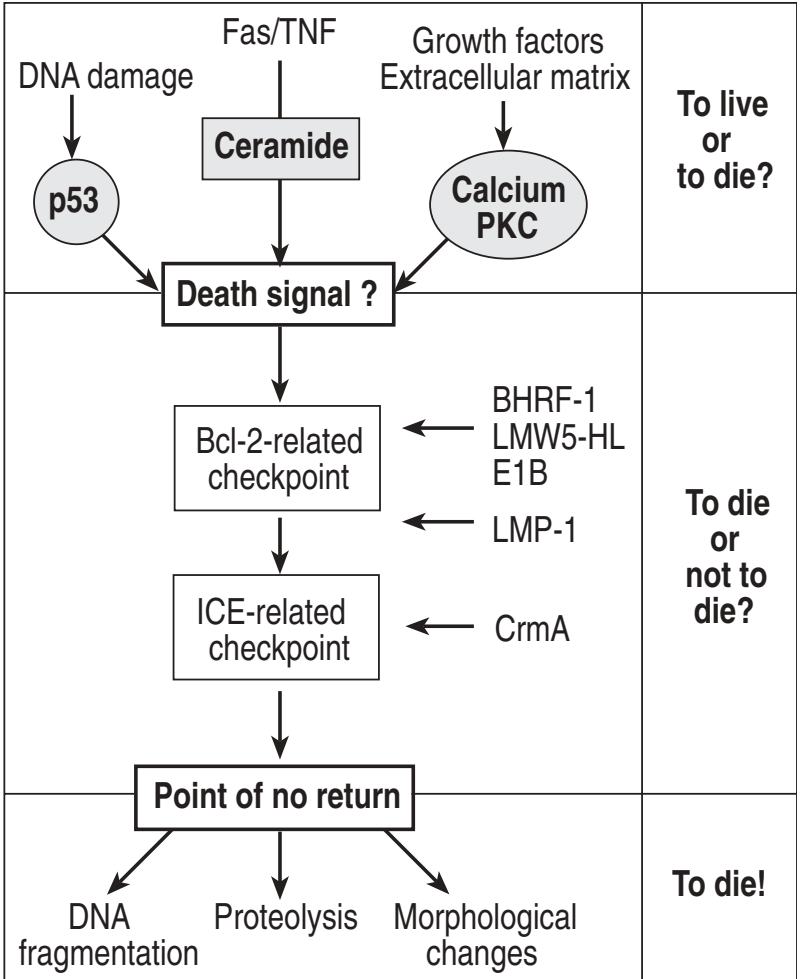

Fig. 1. - The three steps of the apoptotic process. During the first step, intracellular and extracellular signals activate specific pathways that will determine whether a cell should live or die. The tumour suppressor gene $p 53$ is involved in a checkpoint that decides whether a cell progresses in the cell cycle or dies by apoptosis in response to deoxyribonucleic acid (DNA) damage. Interaction of Fas ligand or tumour necrosis factor (TNF) with their membrane receptor increases intracellular ceramide level. Growth factors or interactions with extracellular matrix increase intracellular calcium and activate the protein kinase $\mathrm{C}(\mathrm{PKC})$. The second step involves two checkpoints that could regulate the final cell death pathway. One checkpoint is controlled by proteins from the Bcl-2 family. Bcl-2 expression can be increased by interaction with viral proteins (BHRF-1 from Epstein-Barr virus, LMW5HL from the swine fever virus, and E1B from adenovirus) or mimicked by LMP-1 from Epstein-Barr virus. The other checkpoint could be determined by the cysteine proteases related to interleukin-1 $\beta$ (IL$1 \beta$ ) converting enzyme (ICE) that is inhibited by the CrmA protein from cowpox virus. The cell death pathway then reaches a point of no return, and apoptosis is associated with internucleosomal DNA fragmentation, proteolysis of several nuclear and cytosolic proteins, and characteristic morphological changes.

Much of our knowledge about the specific steps that regulate this cell death pathway has been derived from genetic studies of the nematode Caenorhabditis elegans [12]. Among the 14 genes whose mutation affects the various steps of programmed cell death in this nematode, three genes affect the death process itself, namely ced-3 and ced-4, that are required for cells that must die to undergo programmed cell death, and ced-9 that is required to protect cells that should live from undergoing apoptosis. The ced-3 gene encodes a protein that is similar to the family of cysteine proteases, which includes interleukin$1 \beta$-converting enzyme (ICE), Nedd2/Ich-1, CPP32/Yama, Tx/Ich-2 and Mch2 (for review see [13]). These proteases share a pentameric peptide, QACRG, surrounding a putative activated site Cys. Accordingly, overexpression of these proteases in mammalian cells causes apoptosis, and the cowpox virus crmA gene product, that inhibits some ICE-like proteases, can protect mammalian cells against apoptosis induced by growth factor withdrawal [14]. By contrast, the protein encoded by the ced4 gene has no similarity with other known proteins. The protein encoded by ced-9 is homologous to the Bcl-2 family of cell death regulators identified in mammalian cells, and the expression of the human Bcl-2 in nematodes partially substitutes for the loss of ced-9 function [15]. Studies performed on the role of cysteine proteases and Bcl-2-related proteins suggest that these two components define two checkpoints in the final common pathway that decides whether or not a cell should die.

\section{To die!}

When the final common pathway has allowed the execution of the cell suicide programme, characteristic morphological changes of the dying cell [16] precede the production of apoptotic bodies, membrane-enclosed particles containing intracellular material (fig. 1). These particles are rapidly engulfed and digested by neighbouring cells and phagocytes to prevent any release of intracellular material that would otherwise trigger an inflammatory response, as observed during necrosis. Apoptosis is usually associated with the activation of one or several nucleases that degrade nuclear DNA first into large and subsequently into very small fragments $[17,18]$. One of the consequences of DNA fragmentation is the irreversible degradation of viral or mutated cellular DNA. Proteolytic cleavage of several nuclear proteins by an activity similar to but distinct from ICE is another biochemical marker of apoptotic cell death [19-21].

\section{Apoptosis and the pathogenesis of disease}

\section{Diseases due to defective cell death}

The failure of cells to undergo apoptosis might be involved in the pathogenesis of several human proliferative disorders characterized by the accumulation of cells, including cancer, autoimmune diseases and certain viral infections (fig. 2).

Apoptosis and cancer. Cancer is usually envisaged as a disease of excessive cellular proliferation. Recently, genetic alterations that dysregulate the physiological cell death process appeared to contribute to the clonal expansion of malignant cells. Accordingly, a number of oncogenes and anti-oncogenes have been found to regulate apoptotic cell death. Oncogenes that promote cell proliferation and those that inhibit cell death could co-operate to induce a neoplastic lesion. Genetic alterations that induce cell proliferation, such as dysregulation of either myc or ras proto-oncogenes, would lead to the induction of apoptosis $[6,22]$, unless simultaneous expression of an oncogene, such as $b c l-2$, that inhibits this apoptotic response allows the cell transformation to occur [23]. The best example of these oncogenes is $b c l-2$, identified at the site of a chromosomal translocation between chromosomes 14 and 18, present in most human follicular lymphomas, (for review, see [24]). Upregulation of $b c l-2$ oncogene expression specifically inhibits apoptosis induced by a 


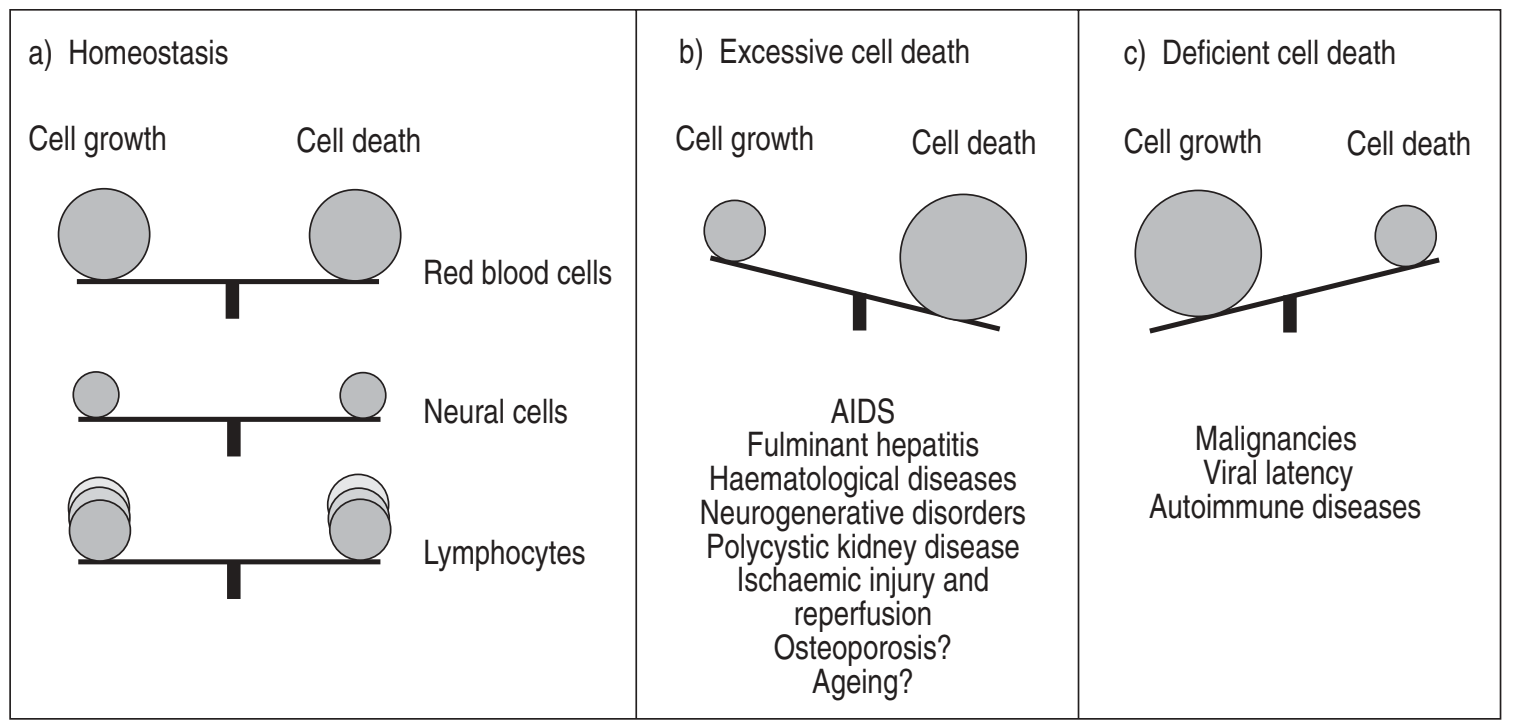

Fig. 2. - a) The level of cell death and cell growth varies widely from one cell lineage to another. b) Excessive; or c) deficient apoptosis are suspected to be involved in the pathogenesis of various diseases. AIDS: acquired immune deficiency syndrome.

wide range of insults and stimuli such as growth factor deprivation, loss of contact with extracellular matrix, cytotoxic T-cells, cytotoxic lymphokines, chemotherapeutic drugs and radiations [24-27]. As indicated previously, human $b c l-2$ can promote cell survival in lower organisms, such as nematodes, and substitute for the loss of function of ced-9 [15]. An elevated level and aberrant pattern of Bcl-2 protein expression have been found in a wide variety of human cancers, including lymphomas, leukaemias, adenocarcinomas, neuroblastomas, renal and lung cancers and melanomas [24]. In most of these tumours, dysregulation of $\mathrm{bcl}-2$ gene expression is not the consequence of the $\mathrm{t}(14 ; 18)$ chromosomal translocation. Structural alterations of the $b c l-2$ gene are not detected in most leukaemias and solid tumours, suggesting that transregulatory rather than cis-regulatory mechanisms account for overexpression of Bcl-2. This overexpression can represent either an early or a late event in the tumour progression. For example, disturbances in the pattern of $b c l-2$ expression represent an early event in colorectal cancers, whereas it occurs later in prostate cancer, in which elevation of $\mathrm{Bcl}-2$ protein level is associated with acquisition of a metastatic and androgen-independent phenotype [24].

One of the potential transregulators of $b c l-2$ that can become altered in cancer is the tumour suppressor $p 53$, which represses $b c l-2$ gene expression [28]. Germ-line p53 mutations predispose individuals with Li-Fraumeni cancer syndrome to the development of tumours, and the p53 gene becomes inactivated in over half of all human tumours [29]. The wild-type p53 protein binds DNA and functions, at least in part, as a transcriptional regulator, activating or repressing the expression of various target genes involved in DNA replication and repair. Wild-type p53 functions primarily to suppress neoplastic growth by inducing apoptosis [30], and contributes to tumour suppression by inducing cell cycle arrest at the G1/S checkpoint in response to DNA damage, in order to facilitate DNA repair [31]. The p53 is also an inducer of apoptosis in certain normal tissues, such as myeloid progenitors and epithelial stem cells [32]. Its presence or absence is an important determinant of the relative sensitivity of normal and tumour cells to apoptosis induced by DNA damaging therapeutic agents [7, 30].

In addition to repressing $b c l-2$ gene expression, p53 transactivates the expression of a homologue of $\mathrm{bcl}-2$ termed bax $[28,33]$. In contrast to Bcl-2, the protein encoded by bax functions as a promoter of cell death. Bax and $\mathrm{Bcl}-2$ are members of a larger family of proteins that can either promote or repress apoptosis [34], including Bcl-x, mcl-1, A1, BAK, Bad, and BAG-1 [35-40]. These proteins can interact through heterodimerization [41]. The functional significance of these interactions remains unknown. Bcl-x can be expressed under two different isoforms, resulting from alternative splicing of $b c l-x$ messenger ribonucleic acid (mRNA) [35]. Bcl-xl, that functions as a death inhibitor, is markedly elevated in several tumours, whereas Bcl-xs could promote cell death by sequestering Bcl-2 so that it cannot interact with Bax and other proteins. Other oncogenes, such as $c-a b l$, are potent inhibitors of apoptosis by a mechanism that seems to be independent of Bcl-2 and Bcl-2-related proteins but remains unexplained [42, 43]. Interestingly, neither mutations of ICE and ICE-related proteases nor their inhibition by viral products, such as CrmA, have so far been implicated in oncogenesis.

Apoptosis and viral latency. Cells infected with a virus can undergo apoptosis as a defence mechanism to prevent viral infection. Infected cells can also express viral peptides in association with cell surface major histocompatibility class I molecules, in order to be recognized and killed by cytotoxic T-cells. T-cells will induce apoptosis, either by using perforin to introduce proteases into the target cell [44], or by activation of the Fas receptor on its surface (see below). A number of viruses disrupt the normal regulation of apoptosis within infected cells to circumvent the host defences. To reach this goal, viral genes encode inhibitory proteins, most of which target one of the two main checkpoints of the final common pathway that leads to apoptosis. The cowpox virus gene, crmA $[14,45]$, encodes a protease inhibitor that prevents 
apoptotic cell death by specifically inhibiting ICE, a key protease in the final pathway of Fas- and tumour necrosis factor- $\alpha$ - mediated cell death $[46,47]$. Other viral genes encode a protein with structural and functional similarities with Bcl-2: they include the $B H R F-1$ gene of Epstein-Barr virus, the LMW5-HL gene of African swine fever virus, and the $E 1 B$ gene of adenovirus [24, $48,49]$. The product of some viral genes, such as LMP1 from Epstein-Barr virus, can upregulate Bcl-2 to allow the establishment of viral latency [50]. The mechanism by which the $p 35$ gene, identified in baculovirus as a potent inhibitor of apoptosis, inhibits cell death in infected cells is still not understood. Interestingly, another baculovirus gene that inhibits apoptosis, namely inhibitor of apoptosis protein $(I A P)$, is analogous to a gene recently involved in the pathogenesis of a recessive neurodegenerative disorder observed in children [51]. Although biochemical mechanisms by which viral proteins inhibit cell death remain poorly explained, nitric oxide produced by human B-lymphocytes was recently reported to contribute to the maintenance of viral latency in downregulating the expression of an Epstein Barr virus early antigen [52].

Apoptosis and autoimmune diseases. Several recent studies have implicated apoptosis in the pathogenesis of autoimmune diseases. The human organism protects itself from autoimmune reactions by clonal deletion of autoreactive T-cells, a process called negative selection. One mechanism by which negative selection takes place is apoptosis. Alterations in the susceptibility of lymphocytes to die by apoptosis in vitro have been reported in several autoimmune diseases, such as systemic lupus erythematosus, rheumatoid arthritis, autoimmune diabetes mellitus or inflammatory bowel disease [53]. Serum proteins could also be involved: serum from patients with type 1 diabetes mellitus, an autoimmune disease associated with the destruction of pancreatic beta cells, was shown to contain a factor that promotes $\mathrm{Ca}^{2+}$-mediated apoptosis in beta cells [54].

Animal model systems have provided new information about the potential role of dysregulated apoptosis in autoimmune diseases. Linkage analysis has established an association between the $b c l-2$ locus and autoimmune diabetes in nonobese diabetic mice [55]. A lupus-like autoimmune disease has been reported in transgenic mice constitutively expressing Bcl-2 in their B-lymphocytes [56]. The most informative observations to date were performed in the MRL mouse strain. Spontaneous autosomal recessive mutation on either chromosome 19 (locus $l p r$ for lymphoproliferative disease) or chromosome 1 (locus gld for generalized lymphoproliferative disease) were observed to accelerate the occurrence of a spontaneous autoimmune disease observed in these mice [57, 58]. Both MRL lpr/lpr and MRL gld/gld mouse strains show a similar phenotype. Mice develop lymphadenopathy and splenomegaly, produce large amounts of anti-DNA and rheumatoid factor autoantibodies, and die of nephritis or arthritis at approximately 5 months of age. Both $l p r$ and gld were shown to be loss-of-function mutations that affect genes encoding a pair of interacting proteins: lpr mutation affects a cell surface protein named Fas (or APO-1 or CD95); whereas, gld affects a soluble or membrane-bound cytokine, which is called Fas ligand (for review see [59]). Molecular and cellular characterization of Fas and Fas ligand in animals and humans revealed their homology with members of the tumour necrosis factor (TNF) receptor family and TNF family, respectively [60, 61]. Fas ligand binds to its receptor Fas, thus inducing apoptosis of the Fas-bearing target cell. Triggering of this apoptotic pathway requires the cross-linking of Fas with either purified Fas ligand, or cells expressing Fas ligand or antibodies to Fas [59]. It has recently been demonstrated that activated Fas interacts with several cellular proteins [62-65], and activates a sphingomyelinase-dependent pathway [66]. Fas-mediated apoptosis is triggered by ICE or ICE-like proteases [46, 47].

Fas is abundantly expressed in activated lymphocytes and in the primary cells from various other tissues, such as liver, heart, lung and ovary. Fas ligand is expressed predominantly in activated CD4+ and CD8+ T-cells and natural killer (NK) cells. The Fas/Fas ligand system is involved in the clonal deletion of autoreactive T-cells in the periphery, not in the thymus. The system is also involved in the deletion of T-cell receptor (TCR)-activated mature T-cells that is necessary to limit every immune response $[67,68]$, and in the mechanisms that cytotoxic T-cells use to kill infected target cells, a pathway distinct from the perforin-mediated pathway (for review see [69]). Genes other than Fas or Fas ligand are probably involved in Fas-related pathology, because $l p r$ mutations induce nephritis or arthritis in MRL mice but not in $\mathrm{C} 3 \mathrm{H}$ mice [70].

In humans, two recent studies identified Fas gene mutations in children who developed a rare autoimmune lymphoproliferative disorder, characterized by massive nonmalignant lymphadenopathy, autoimmune phenomena and expanded populations of immature lymphocytes [7173]. An elevated level of the soluble form of Fas was detected in the serum of some patients with systemic lupus erythematosus. It was suggested that the soluble form of Fas could inhibit Fas-mediated elimination of autoreactive lymphocytes [74]. A soluble form of Fas ligand was also identified as an homotrimer in the culture medium of activated human T lymphocytes. If such a molecule is produced in vivo, it may work as an agent that causes systemic tissue damage [75]. The primary cells from several tissues are sensitive to Fas-mediated apoptosis, suggesting that the Fas system may be involved in cytotoxic T-lymphocyte (CTL)-mediated diseases in these tissues [59]. Bone marrow transplantation performed between $l p r$ mutant and wild-type MRL mice have suggested that Fas system may be involved in the graftversus-host disease induced by allogenic bone marrow transplantation in humans [59].

\section{Diseases related to excessive cell death}

Fas-mediated diseases. A variety of diseases characterized by excessive cell loss may result from accelerated rates of cell death. Besides defective Fas-signalling involved in lymphoproliferative disorders, Fas-related diseases may be caused by excessive activity of the Fas system. Abnormal activation of Fas ligand expressed on cytotoxic T-cells could be involved in human fulminant hepatitis. Intraperitoneal injection of a cytotoxic monoclonal antibody generated against mouse Fas has been shown to kill wild-type mice by inducing fulminant hepatitis. Two hours after 
injection, the serum level of glutamate oxaloacetate transaminase (GOT) and glutamate pyruvate transaminase (GPT) increased rapidly and reached about 200 and 1,000 fold above basal level, respectively. Histochemical analysis showed massive haemorrhagic necrosis in the entire liver, and electron microscopy of the affected hepatocytes revealed condensed and fragmented nuclei, an aspect characteristic of apoptosis. It was concluded that the anti-Fas antibody had caused the hepatocytes to die. It was suggested that rapid and widespread cell death had not allowed the macrophages to remove the apoptotic cells, resulting in secondary necrosis and release of lethal toxic components. Anti-Fas antibody injection did not kill MRL lpr/lpr mice [76]. Primary hepatocytes are sensitive to Fas-mediated apoptosis in vitro. Fas is overexpressed in hepatocytes transformed by human hepatitis $\mathrm{C}$ virus. Injection of CTLs specific for the human hepatitis B virus in transgenic mice carrying the virus induced fulminant hepatitis [77-79]. These observations are consistent with the hypothesis of involvement of Fas system in the occurrence of fulminant hepatitis when hepatocytes are infected with hepatitis $\mathrm{B}$ or $\mathrm{C}$ viruses. The process may normally occur to remove virus-infected cells but, when exaggerated, could lead to fulminant hepatitis. Similarly, Fas system may be involved in other CTL-mediated autoimmune diseases, such as chronic thyroiditis $[6,59]$.

Acquired immune deficiency syndrome. AIDS is characterized by a progressive and selective depletion of the CD4+ population of T-lymphocytes. The exact mechanisms by which the human immunodeficiency virus-1 (HIV-1) kills immune cells is not understood. Most Tcells that die during HIV infection do not appear to be infected with the virus, and the number of apoptotic Tcells does not correlate with progression of disease [80]. Nevertheless, a growing body of experimental evidence suggests a role for apoptosis in CD4+ T-cell depletion. Enhanced apoptosis has been observed in primate models of lentiviral infections, as well as in lymphocytes and lymph nodes from AIDS patients. Picomolar concentrations of the soluble viral product, gp120, were reported to prime human CD4+ T-cells for activation-induced cell death [81]. More recently, HIV-1 Tat protein was shown to induce cell death by apoptosis in a T-cell line and in mononuclear peripheral blood cells from uninfected donors [82]. Tat protein was shown to induce in T-cells a premature activation of cyclin-dependent kinases, an event that has been associated with apoptosis induction in several other cell systems. Tat-activated T-cells would then be depleted when either the T-cell receptor is activated by an antigen or when gp120 binds to CD4 receptor. Fas could be involved in the death of CD4+ T-cells during the course of an HIV infection [83]. Human T-cell lines, transformed with HIV, are more sensitive to Fasmediated apoptosis than the parental cells. Fas is highly expressed on T-cells of mice with retrovirus-induced immunodeficiency syndrome and on T-lymphocytes of HIV-infected children. The current hypothesis is that HIV-1 Tat and gp120 accelerate Fas-mediated, activation-induced T-cell apoptosis, therefore contributing to CD4+ T-cell depletion during the course of AIDS [82] (fig. 3). Viral replication itself may not be limited by CD4+ T-cells death because CD4 receptor is downregulated on infected cells, which could prevent both viral

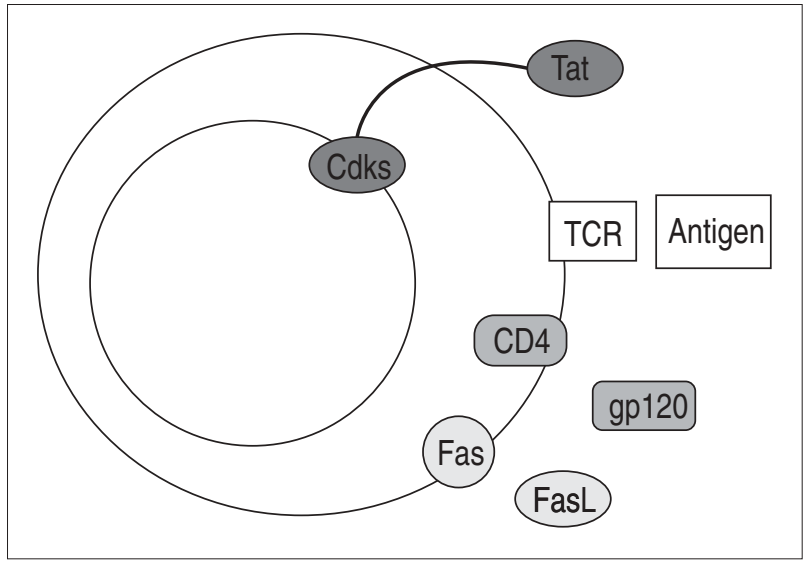

Fig. 3. - Factors of the CD4+ T-cell depletion in acquired immune deficiency syndrome. The current hypothesis is that two viral proteins produced by human immune deficiency virus-1 (HIV-1)-infected cells, namely Tat and gp120, prime activated CD4+ T-cells for apoptosis mediated by the Fas system (interaction of a soluble ligand and a membrane receptor). T-cell activation is triggered by an interaction between an antigen and the T-cell receptor (TCR). The soluble viral product, gp120, binds to CD4 receptor. The viral protein tat induces a premature activation of cyclin-dependent kinases (Cdks), an event that has been associated with induction of apoptosis in several other cell systems. The membrane receptor Fas is highly expressed on retrovirallyinfected T-cells.

reinfection and CD4-mediated apoptosis. Lymphocyte apoptosis has also recently been involved in the pathogenesis of the leukaemia-like disease induced by the human T-lymphocyte virus-1 (HTLV-1) infected T-cells [84], and virally-induced abortive activation of T-cells may be a response to several other viral infections in mammals [85].

Haematological diseases. Haematopoietic growth factors, including stem cell factor, colony-stimulating factors, erythropoietin and thrombopoietin, play a key role in the regulation of haematopoiesis. These factors were demonstrated to act, in part, by promoting the survival of progenitor cells, by suppressing apoptosis during the differentiation of intrinsically committed progenitors [2, 4]. Overexpression of Bcl-2 prevents apoptosis of haematopoietic cells induced by growth factor withdrawal [86]. Bone marrow-derived stromal cells also prevent apoptotic death of normal and malignant haematopoietic cells [11]. Haematological diseases, such as myelodysplastic syndromes, aplastic anaemia, chronic neutropenia or severe $\beta$-thalassaemia are associated with increased apoptotic cell death within the bone marrow [87-89]. The mechanisms by which increased apoptotic cell death is involved in the aetiology of these diseases remains unexplained and could involve stroma cell deficiencies, gene deregulation and direct effects of toxins or mediators of the immune response.

Neurodegenerative disorders. The same mechanisms could apply for the increased apoptosis of specific sets of neural cells described in several neurological diseases such as Alzheimer's and Parkinson's diseases, or cerebellar degeneration [90-91]. Like haematopoietic growth factors and bone marrow stromal cells, several specific and less specific growth factors and extracellular matrix prevent 
neural cell apoptosis, an effect that can be mimicked by overexpressing Bcl-2 in the neural cells [92-94]. Several gene mutations that lead to increased apoptotic cell death were identified in neurodegenerative disorders. Mutations in a superoxide dismutase gene were identified in patients with autosomal dominant amyotrophic lateral sclerosis [95]. These mutations decrease the ability of motor neurons to detoxify oxygen-free radicals. Mutations in any of the three photoreceptor-specific genes lead to photoreceptor apoptosis and retinal degeneration observed in patients with retinal pigmentosa [96]. Either dysfunction of the mutated protein or its accumulation could be responsible for increased apoptosis. Mutations in the neuronal apoptosis inhibitory protein (NAIP) gene, a gene homologous to IAP from baculovirus, have been identified in spinal muscular atrophy and may decrease the apoptotic threshold of spinal cord neurons [51].

Other diseases. Although apoptotic cells are phagocytosed within a few hours by neighbouring cells, apoptosis has been demonstrated histologically and histochemically to occur in several disease. Apoptosis is a pathological feature of polycystic kidney disease [97], and toxic-induced liver diseases [98], and may be central to the pathogenesis of these diseases. Ischaemic injury, such as myocardial infarction or stroke, induces the rapid death of cells within the central area of ischaemia by necrosis. Outside the central ischaemic zone, cells die over a more protracted time period by apoptosis. Rapid reperfusion of acutely occluded blood vessels induces an increase in free radical production and in intracellular calcium level, which both trigger apoptosis of cardiac myocytes [99]. Apoptosis has recently been described in atheroma, in which its pathogenic role remains to be explained [100, 101]. Degenerative disorders of the musculoskeletal system, including arthritis and osteoporosis, could also be the consequence of increased apoptosis of chondrocytes and osteocytes, respectively. Lastly, tissue homeostatic control is altered during the course of ageing, and the equilibrium is shifted toward cell death. The true nature of this age-related cell deletion phenomenon could be apoptosis [102], as a consequence of diminished synthesis of various growth factors, transmembrane signalling defects, inability to cope with oxidative stress, or abnormal cell cycle regulation [103]. Conversely, senescence can be associated with defective apoptosis: Fas expression and Fas ligand-induced apoptosis are decreased in T-cells from old mice compared to young mice [104]. Tcells from old mice also demonstrate a markedly decreased response to anti-CD3 stimulation [104, 105].

\section{Other relationships between apoptosis and diseases}

Another relationship between autoimmune diseases and apoptosis was suggested by the recent observation of ultra violet (UV)-irradiated cultured human keratinocytes. Systemic lupus erythematosus (SLE) is often regarded as the prototypic systemic autoimmune disease. This disease is characterized by an autoantibody response directed against selected intracellular antigens. The skin plays an important role in the disease, that can appear after extended exposure to sunlight. UV-induced apoptosis of the keratinocytes is associated with the clustering of potentially immunogenic cellular components in apoptotic blebs, a process that might participate to the induction of autoantibodies directed at multiple antigens [106]. A similar phenomenon could be involved in the development of an immune response to cancer cells, as suggested by recent observations in a regressive/progressive model of rat colon carcinoma cells (F. Martin, personal communication).

Identification of apoptosis is suggested to be a useful criterion in the assessment of response to various treatments, such as hormonal treatment of prostate cancer [107], and radiotherapy of cervical carcinoma [108]. Excessive toxicity of some treatments could also involve induction of apoptosis; toxicity of L-DOPA for the treatment of Parkinson's disease was recently related to the induction of apoptosis in target cells, suggesting that modulation of this phenomenon could prevent the acceleration of neuronal damage in this disease [109].

\section{Apoptosis and the treatment of diseases}

Based on the observation of the role of deficient or excessive cell death in the pathogenesis of several diseases, new therapeutic strategies could be designed to enhance or decrease the susceptibility of individual cell types to undergo apoptosis. Treatments that restore the ability of target cells to properly undergo apoptosis in response to a given signal could be of benefit in diseases with deficient cell death, such as malignancies. Conversely, treatments that increase the apoptotic threshold may be of benefit in disorders associated with cell loss, such as degenerative disorders. During the past 5 yrs, studies performed in vitro and sometimes in vivo have identified a large number of agents that either inhibit or induce apoptosis.

\section{Therapeutic strategies targeting the nucleus}

Nuclear changes and internucleolytic cleavage of nuclear DNA are observed at an early stage of apoptosis in many cell systems [18]. Therefore, endogenous activation of an endonuclease activity was suspected to be an essential step in the apoptotic process. Chromatin structure plays a determinant role in DNA fragmentation, that will take place only when linker regions separating nucleosomes are made accessible by a decondensation or local reduction in histone-DNA interaction. Spermine, a polyamine that modifies the degree of chromatin accessibility, can prevent DNA fragmentation in several cell systems [110]. Zinc and aurintricarboxylic acid inhibit oligonucleosomal DNA fragmentation associated with apoptosis in several cell systems [110]. Accordingly, zinc depletion can induce cell death by itself. The effect of zinc has been attributed to a direct inhibition of the putative endonuclease [18]. Zinc could have other cellular effects, since it is a cofactor of several enzymes, such as poly(ADP)polymerase or the nuclear DNA topoisomerase I that could be involved in apoptosis. Zinc may also stabilize the association of protein-DNA complexes, which in turn may act on chromatin structure. However, both purpose and mechanisms of DNA fragmentation in apoptotic cells remain unclear. Recent studies have demonstrated 
that internucleosomal DNA fragmentation is preceded by, and sometimes limited to, the formation of high molecular weight DNA fragments, referred to as "domain" cleavages [111]. This fragmentation is not inhibited by zinc, and may be due to topoisomerase II. Whether inhibitors of topoisomerase II that do not stabilize cleavable complexes could be good therapeutic tools to prevent this fragmentation remains to be determined. Cells without a nucleus can be induced to undergo the characteristic cytoplasmic changes of apoptosis $[112,113]$ while oligonucleosomal DNA fragmentation can be induced in isolated nuclei $[8,18,19,114]$, suggesting that structural and biochemical changes of each cellular compartment occur independently. For all these reasons, therapeutic strategies designed to prevent nuclear changes will not inhibit the whole process [115], and internucleosomal DNA fragmentation is an event that probably occurs too late to be a good therapeutic target.

\section{Therapeutic strategies targeting the final common path- way}

A more convincing target for the treatment of diseases is the final common pathway that involves the products of the Bcl-2 family and ICE-related cysteine proteases. Several lines of evidence indicate that these central components of the cell death machinery are most likely to be localized to the cytosol. This pathway is regulated by a balance between the opposing activities of proteins that promote and those that inhibit cell death. Several pairs of inducers and repressors such as Bcl-xl/Bcl-xs [35] and Ichll/Ichls [116], are issued from the same gene by alternative splicing. At least five isoforms of ICE have recently been identified as resulting from alternative splicing, some inducing and others repressing cell death [117]. The functional role of these numerous members of Bcl2 and ICE family remains unknown at present. How could the recent and still incomplete knowledge of the checkpoints that regulate the final common pathway of apoptosis be used to improve the treatment of diseases?

The involvement of Bcl-2 overexpression in the resistance to essentially all cytotoxic anticancer drugs suggests that inhibition of the protein expression or activity could make it possible to increase the sensitivity of tumour cells to chemotherapeutic agents. Schematically, three main levels of cellular resistance to cytotoxic drugs have been identified: the first level includes the mechanisms that prevent the drug from reaching its target, most often localized in the nucleus. The most studied of these mechanisms is P-glycoprotein mediated drug efflux. The second level concerns the interactions between the drug and its intracellular target, whose quantitative or qualitative changes can prevent the drug from inducing specific damage. More recently, a third level was identified that is independent of the drug and concerns the ability of the cell to trigger its apoptotic machinery in response to specific damage induced by the drug [118-120]. Therefore, the intrinsic killing power of a drug could be less important than the ability to induce the tumour cells into killing themselves. In cells overproducing Bcl-2 due to gene transfer manipulations, the drug enters the cell at a normal rate and induces specific molecular damage [24]. Bcl-2 increases the threshold of specific molecular damage that is necessary to generate the biochemical events that will lead to apoptotic cell death, for example activation of cysteine proteases and endonucleases [27]. Upon removal of the drug, Bcl-2-protected cells can repair drug-induced damage and resume their proliferation. These unique functional properties of Bcl-2 presumably account for the poor clinical outcome associated with $b c l-2$ overexpression in some series of patients with low grade follicular non-Hodgkin's lymphoma, acute myeloblastic leukaemia and solid tumour [121].

The inhibitory properties of $\mathrm{Bcl}-2$ could be used to protect normal cells from chemotherapy-induced cell death. Enforced expression of $b c l-2$ gene in bone marrow cells, using retroviral gene transfer techniques, was demonstrated to rescue these cells from apoptosis induced by topoisomerase inhibitors [122]. Conversely, specific strategies that will decrease $\mathrm{Bcl}-2$ expression in tumour cells that overexpress the protein could increase their sensitivity to chemotherapeutic drugs and radiation. Antisense oligonucleotides have been successfully tested to specifically decrease $b c l-2$ expression in vitro, and this inhibition increases leukaemic cell sensitivity to cytotoxic agents [123]. These short stretches of synthetic singlestrand DNA enter the cell, bind to specific messenger ribonucleic acid (mRNA) sequences and prevent the expression of the corresponding protein. A similar strategy was also tested in a cell line derived from a patient with chronic myeloid leukaemia, a disease in which a $t(9 ; 22)$ chromosomal translocation generates a chimeric bcr-abl protein with constitutive c-abl kinase activity [44]. Increased abl kinase activity induces a high level of cellular resistance to induction of apoptosis by a variety of stimuli, including chemotherapeutic drugs [42]. Again, antisense oligonucleotides, corresponding to bcr-abl, have proved efficient at increasing the sensitivity of the bcrabl positive cell line to cytotoxic agents [43]. In some cell lines with either $b c l-2$ overexpression or $b c r-a b l$ rearrangement, specific antisense oligonucleotides can inhibit cell growth and induce apoptosis without additional treatment [124].

Although such antisense intervention might have potential clinical application, the therapeutic use of oligonucleotides has been shown to be problematical for a variety of reasons. A better strategy would be to identify agents that specifically interfere with the biochemical mechanisms by which either Bcl-2 or bcr-abl inhibit the apoptotic process. Unfortunately, these biochemical mechanisms have not yet been clearly identified.

Inhibition of the expression or function of Bcl-2, a protein involved in the final pathway that seems to be common to numerous forms of apoptosis, could not be specific enough to be a good therapeutic strategy. Recent data analysing a Bcl-2 loss of function murine model suggest that the function of Bcl-2 is absolutely necessary only in a limited number of normal cell types or, alternatively, there is a redundancy within the Bcl-2 family such that specific loss of $\mathrm{Bcl}-2$ is relatively well-tolerated [125]. Therefore, short-term treatment with the antisense oligonucleotide anti- $b c l-2$ may not be as toxic as might initially have been expected. Targeting Bcl-x, a Bcl-2 related protein whose isoform $\mathrm{Bcl}-\mathrm{xL}$ also inhibits drug-induced apoptosis, could be more toxic, since Bcl-x deficient mice demonstrated extensive apoptotic cell death of neurons and haematopoietic progenitors [126]. 
Bcl-2 overexpression has not been associated with poor clinical outcome in all types of malignant tumours. Recent reports suggest a better prognosis in some tumours with increased Bcl-2 expression. This clinical observation could have several explanations. Firstly, growth factors were demonstrated to modulate the expression [127, 128], and to induce post-transcriptional modifications of the protein [24] that could modulate its activity. Better understanding of this regulation could suggest therapeutic use of this modulating activity. Secondly, Bcl-2 activity is modulated by heterodimerization with several other proteins from the Bcl-2 family, for example Bax [41]. Bax functions as a promoter rather than a repressor of cell death [33]. Relationships between the two proteins is enforced by the observation that $\mathrm{p} 53$, both represses $\mathrm{bcl}$ 2 expression and promotes Bax expression [28]. A cell with low Bax expression would require only low levels of Bcl-2 to reach the critical stoichiometry at which Bcl2/Bax dimer form, and reprieve from death is assured. Conversely, high Bax levels could render the cell more sensitive to death and more difficult to rescue. Accordingly, several tumours demonstrated marked reduction in Bax expression, sometimes associated with p53 mutations and/or drug resistance. Finally, interactions of Bcl2 with other proteins from the Bcl-2 family could induce the specific inhibition of some apoptotic pathways. For example, Bcl-2 needs to interact with BAG-1 to efficiently prevent apoptosis induced by the Fas signalling pathway [40]. Therefore, modulation of Bcl-2 activity may require pharmacological agents that mimic or prevent specific interactions between proteins of the Bcl-2 family in order to be more specific with regard to the cell type and the stimuli.

Proteases involved in the final common pathway that leads to apoptosis, mainly ICE and ICE-related protein family, constitute another potential therapeutic target. Again, alternative spliced forms of members of ICE family, such as Ich11 and Ich1s, can have opposite effects [116]. This suggests that cysteine protease inhibitors that are specific for each member of the family, and pharmacological agents that modulate interactions between these members, may be developed [129-131]. These agents exist in nature: granzyme A and B, synthesized by cytotoxic T-cells, are ICE-related proteases that directly activate the apoptotic machinery in the target cell [132]. Conver-sely, several viruses synthesize proteins that either mim-ic Bcl-2 (BHRF1 from EBV, E1B from adenovirus, and LMW5-HL of African swine fever virus) or stimulate Bcl-2 expression (LMP-1 from EBV) or inhibit ICE (CrmA from cowpox virus) $[49,50]$. Generation of attenuated viruses that do not express the genes which allow them to establish latent infection could be used for vaccination.

\section{Therapeutic strategies targeting more specific pathways}

Other targets for the therapeutic modulation of apoptosis are the different signalling pathways that activate the central cell death machinery. Most inducers of apoptosis use a specific signalling pathway. DNA damaging agents use a p53-dependent pathway. In leukaemic cells, activation of Fas and TNF receptors induces sphingomyelin hydrolysis and ceramide production. In thymocytes, interaction of cytokines and growth factors with their membrane receptors activates a calcium-dependent pathway. Only cytotoxic T-cells induce apoptosis by delivering in the target cells several proteases (or granzymes), some of them mimicking the activity of ICE. It is very important to understand how early steps of apoptosis are activated through the cell, because this may make it possible to define successful strategies. Nitric oxide (NO) synthase expression and NO production are increased in MRL $l p r / l p r$ mice, and spontaneous glomerulonephritis and arthritis can be reduced by oral administration of $\mathrm{N}$ mono-methyl-arginine, which inhibits NO production [59]. Early HIV infection is associated with reduced glutathione levels in blood cells. The pro-oxidant state associated with HIV infection may result in perturbations of activation-induced signal transduction in T-lymphocytes, which may be related to the enhanced tendency of these cells to undergo apoptosis [133]. Beneficial effects could be obtained by treatment of HIV-infected individuals with antioxidants, such as N-acetylcysteine [134].

Again, malignant cells provide a good example for testing this strategy. Mutations of $p 53$ were suggested to reduce the efficacy of DNA damaging agents in human tumours [7]. The protein p53 is not an element of the final common pathway, since cells lacking p53 can still undergo apoptosis, although some apoptotic stimuli do not function. The protein is an important trigger for apoptosis induced by DNA damage. Two mechanisms were proposed to explain the involvement of p53 in induction of apoptosis in response to DNA damage. A "clash" mechanism suggest's that p53-mediated cell cycle arrest conflicts with oncoprotein driven cell cycle progression stimulus, leading to apoptosis. The "dual pathway" mechanism suggests that the outcome of p53-mediated G1 arrest depends on the cell genotype, i.e. the expression of adenovirus E1A protein [135]. Whatever the true mechanism, p53 mutations have been related to radioresistance, and reintroduction of wild-type $p 53$ was shown to restore cisplatin-induced apoptosis into p53-deficient lung carcinoma cells. Several clinical studies also suggest that the presence of p53 mutations is associated with poor prognosis [136], and sometimes with drug resistance [137], in various cancers. Based on this observation, the identification of p53 mutations in certain tumour types may become an important factor in treatment decision. The use of drugs or gene vectors that restore p53 activity may increase the therapeutic efficacy of DNA damaging agents. Alternatively, identification of p53 mutations should lead to the use of molecules that induce tumour cell apoptosis independently of p53, such as Taxol [138].

A paradox of the immune response leading to T- or B-cell apoptosis could be use for the treatment of autoimmune diseases. Despite the role of acquired immunity in the defence against infectious agents, very high doses of antigen, or prolonged exposure to antigen can suppress $\mathrm{T}$ - and B-cell mediated immune response in adult animals. For example, large numbers of viruses produce antigenic loads that induce the deletion of cytotoxic Tcells and eliminate a recall response. T-cell death was demonstrated to be a physiological response to interleukin-2-mediated cell cycle stimulation and T-cell receptor re-engagement at high antigen doses [139]. On the other hand, hypermutation of immunoglobulin genes in B-cells proliferating within germinal centres during an 
immune response generates variant antibodies that react with higher affinity against either foreign or self antigens. Recent studies have shown that administration of soluble antigen induces the rapid apoptosis of antigenspecific germinal centre B-cells, a mechanism that could cope with affinity maturation of autoantibodies to systemic autoantigens and induce tolerance [140, 141]. This mechanism could have failed in patients with rheumatoid arthritis, who develop antibodies that react with their own immunoglobulin [142]. Specific deletion of lymphocytes by repetitive treatment with a disease-associated autoantigen has been shown to be effective in the treatment of experimental autoimmune encephalitis in mice [139]. Similar treatment strategies may prove effective in human autoimmune disease, if the specific antigens involved in the autoimmune reaction can be identified. A better understanding of the tolerance induced by high doses of antigen could also help immunologists to improve their protocols for inducing specific tolerance to transplantation antigens. Another apoptosis-related strategy for the immunotherapy of autoimmune diseases in vivo would be to deliver an antigen-specific signal to the Tcells in the absence of the second co-stimulatory signal; a strategy that was recently shown to induce specific apoptosis of autoreactive T-cells [143].

If the role of the Fas/Fas ligand system is confirmed in diseases, such as chronic thyroiditis or fulminant hepatitis, induced by hepatitis B or hepatitis C viruses, the soluble form of Fas as well as neutralizing antibodies to Fas or Fas ligand could prove clinically useful. Fas-based reagents (such as activating anti-Fas or FasL) were also considered for the treatment of AIDS, in combination with 3'azido-3'-deoxythymidine, since anti-Fas monoclonal antibodies are cytotoxic to the HIV-infected cells, without increasing HIV infection [144]. These antibodies were also demonstrated to induce apoptosis of leukaemia cells, suggesting they could be used for the treatment of adult T-cell leukaemia [145]. Moreover, anti-Fas antibodies were shown to synergize with toxins and chemotherapeutic drugs to overcome TNF and drug resistance in various human tumour cell lines [146].

Increased expression of Fas in cisplatin- and gamma interferon-treated colon carcinoma cells could make it possible to obtain a synergistic effect of cytotoxic drugs and anti-Fas antibodies (M.T. Dimanche-Boitrel and O. Michaux, personal communication). However, it would be necessary to find a method to accurately target the reagents to the target cells in vivo, in order to avoid the potential risk of these reagents for normal tissues [76]. Targeted gene transfer techniques could resolve this obstacle: CD2-Fas transgene was recently reported to allow the maintenance of Fas apoptosis function and T-cell function in aged mice at a level comparable to that of young mice [104].

The use of cell surface receptors and second messenger systems to regulate cell death responses in vivo may have pleiotropic effects. For example, interleukin-12 (IL12) treatment in vivo has recently been shown to protect bone marrow from gamma irradiation-induced apoptosis; whereas, it potentiates cell death within the gastrointe stinal tract in response to the same stimulus [147]. Haematopoietic growth factors prevent apoptosis of haematopoietic cells that express membrane receptors for these factors and are already in therapeutic use to prevent excessive cell death in patients treated with chemotherapeutic agents [148]. Protection of malignant cells from the cytotoxic effect of the therapeutic compounds suggests that the clinical use of these cytokines in combination with cytotoxic drugs should be carefully timed [149]. Accordingly, a clinical trial that combined granulocyte/macrophage colony-stimulating factor (GM-CSF) and standard induction cytotoxic therapy for the treatment of acute myeloblastic leukaemias suggested a negative effects of the growth factor on the response rate [150]. However, several other trials combining either granulocyte colony stimulating factor (G-CSF) or GM-CSF with chemotherapy did not confirm the negative impact of growth factors; and additional randomized studies will be necessary to determine whether growth factors improve or decrease the response rate of acute myeloblastic leukaemias to chemotherapy [148].

Hormones can prevent apoptosis induced by their deprivation [151]. Conversely, the $\beta$-chain of human chorionic gonadotrophin ( $\beta$-HCG), a pregnancy hormone, was shown to induce in vitro and in vivo cell death, supposed to be apoptosis, in a neoplastic Kaposi's sarcoma cell line [152]. It was proposed that the low rate of Kaposi's sarcoma in women could be due to the interplay of hormones in the regulation of vascular proliferation. HIV1-associated Kaposi's sarcoma has a high incidence among homosexual men. The antitumour properties of $\beta-\mathrm{HCG}$ could offer a new strategy for the treatment of this disease.

In conclusion, there is no doubt that apoptosis is an important factor in the pathogenesis and treatment of numerous diseases. It must be emphasized that apoptosis can certainly not explain all death phenomena observed in human diseases. Nevertheless, the notion that many diseases are related to deregulated cell death, and that new therapeutic strategies can derive from these observations, probably explains the enormous enthusiasm for this area of research.

Acknowledgements: The authors are grateful to F. Martin for his pertinent advice on the manuscript. L.D. is a $\mathrm{PhD}$ student receiving fellowship support from the Ligue Nationale Contre le Cancer in France.

\section{References}

1. Lennon SV, Martin SJ, Cotter TG. Dose-dependent induction of apoptosis in human tumour cell lines by widely divergent stimuli. Cell Prolif 1991; 24: 203-214.

2. Williams GT, Smith CA, Spooncer E, Dexter TM, Taylor DR. Haematopoietic colony-stimulating factors promote cell survival by suppressing apoptosis. Nature 1990; 343: 76-79.

3. Crompton T. IL-3-dependent cells die by apoptosis on removal of their growth factor. Growth Factors 1991; 4: $109-116$.

4. Koury MJ, Bondurant MC. Erythropoietin retards DNA breakdown and prevents programmed cell death in erythroid progenitor cells. Science 1990; 248: 371-378.

5. Strasser A. Death of a T-cell. Nature 1995; 373: 385-386.

6. Evan GI, Wyllie AH, Gilbert CS, et al. Induction of apoptosis in fibroblasts by c-myc protein. Cell 1992; 69: 119-128.

7. Lowe SW, Bodis S, McClatchey A, et al. p53 status 
and the efficacy of cancer therapy in vivo. Science 1994; 266: 807-810.

8. Solary E, Bertrand R, Pommier Y. Differential induction of apoptosis in undifferentiated and differentiated HL-60 cells by DNA topoisomerase I and II inhibitors. Blood 1993; 81: 1359-1368.

9. Raff MC. Social controls on cell survival and cell death. Nature 1992; 356: 397-400.

10. Boudreau N, Sympson CJ, Werb Z, Bissell MJ. Suppression of ICE and apoptosis in mammary epithelial cells by extracellular matrix. Science 1995; 267: 891-893.

11. Manabe A, Coustan-Smith E, Behm FG, Raimondi SC, Campana D. Bone marrow-derived stromal cells prevent apoptotic cell death in B-lineage acute lymphoblastic leukemia. Blood 1992; 79: 2370-2377.

12. Hengartner MO, Horvitz HR. Programmed cell death in Caenorhabditis elegans. Curr Opin Gen Dev 1994; 4 : 581-586.

13. Martin SJ, Green DR. Protease activation during apoptosis: death by a thousand cuts. Cell 1995; 82: 349-352.

14. Gagliardini V, Fernandez PA, Lee RKK, et al Prevention of vertebrate neuronal death by the $\mathrm{crmA}$ gene. Science 1994; 263: 826

15. Hengartner MO, Horvitz HR. C. elegans cell survival gene ced-9 encodes a functional homolog of the mammalian proto-oncogene bcl-2. Cell 1994; 76: 665-676.

16. Arends MJ, Wyllie AH. Apoptosis: mechanisms and roles in pathology. Int Rev Exp Pathol 1991; 32: 223-254.

17. Zhivotovski B, Wade D, Nicotera P, Orrenius S. Role of nucleases in apoptosis. Int Arch Allergy Appl Immunol 1994; 105: 333-338.

18. Earnshaw WC. Nuclear changes in apoptosis. Curr Opin Cell Biol 1995; 7: 337-343.

19. Lazebnik YA, Kaufmann SH, Desnoyers S, Poirier GG, Earnshaw WC. Cleavage of poly(ADP-ribose)polymerase by a proteinase with properties like ICE. Nature 1994; 371: 346-347.

20. Li CJ, Friedman DJ, Wang C, Metelev V, Pardee AB. Induction of apoptosis in uninfected lymphocytes by HIV1 tat protein. Science 1995; 268: 429-431.

21. Jensen PH, Cressey LI, Gjertsen BT, et al. Cleaved intracellular plasminogen activator inhibitor 2 in human myeloleukaemia cells is a marker of apoptosis. $\mathrm{BrJ}$ Cancer 1994; 70: 834-840.

22. Wyllie AH, Rose KA, Morris RG, Stell CM, Forster E, Spandidis DA. Rodent fibroblast tumors expressing human myc and ras genes: growth, metastasis and endogenous oncogene expression. Br J Cancer 1987; 56: 251-259.

23. Vaux DL, Cory S, Adams JM. Bcl-2 gene promotes hematopoietic cell survival and co-operates with c-myc to immortalize pre-B cells. Nature 1992; 335: 440-442.

24. Reed JC. Bcl-2 and the regulation of cell death. J Cell Biol 1994; 124: 1-6.

25. Allsopp TE, Wyatt S, Paterson HF, Davies AM. The proto-oncogene $b c l-2$ can selectively rescue neurotrophic factor-dependent neurons from apoptosis. Cell 1993; 73 : 295-307.

26. Levine B, Huang Q, Isaacs JT, Reed JC, Griffin DE, Hardwick JM. Conversion of lytic to persistent alphavirus infection by the bcl-2 cellular oncogene. Nature 1993; 361: 739-742.

27. Miyashita T, Reed JC. Bcl-2 oncoprotein blocks chemotherapy-induced apoptosis in a human leukemia cell line. Blood 1993; 81: 151-157.

28. Miyashita T, Krajewski S, Krajewska M, et al. Tumor suppressor $\mathrm{p} 53$ is a regulator of $b c l-2$ and bax in gene expression in vitro and in vivo. Oncogene 1994; 9: 1799-1805.

29. Harris CC, Hollstein M. Clinical implications of the $p 53$ tumor suppressor gene. N Engl J Med 1993; 329: $1318-1327$.

30. Kamb A. Sun protection factor p53. Nature 1994; 372: 730-731.

31. Kastan MB, Zhan Q, el-Deiry WS, et al. A mammalian cell cycle checkpoint pathway utilizing p53 and GADD45 is defective in ataxia telangectasia. Cell 1992; 71: 587597.

32. Ziegler A, Jonason AS, Leffel DJ, et al. Sunburn and p53 in the onset of skin cancer. Nature 1994; 372: 773-776.

33. Oltvai ZN, Milliman CL, Korsmeyer SJ. Bcl-2 heterodimerizes in vivo with a conserved homolog, Bax, that accelerates programed cell death. Cell 1993; 74: 609-619.

34. Wyllie AH. Death gets a brake. Nature 1994; 369: 272-273.

35. Boise LH, Gonzales-Garcia M, Posterna CE, et al. bcl$x$, a $b c l-2$-related gene that functions as a dominant regulator of apoptotic cell death. Cell 1993; 74: 597-608.

36. Kozopas KM, Yang T, Buchan HL, Zhou P, Craig RW. $M C L-1$, a gene expressed in programed myeloid cell differentiation, has sequence similarity to $\mathrm{Bcl}-2$. Proc Natl Acad Sci USA 1993; 90: 3516-3520.

37. Kiefer MC, Brauer MJ, Powers VC, et al. Modulation of apoptosis by the widely distributed Bcl-2 homolog Bak. Nature 1995; 374: 736-739.

38. Chittenden T, Harrington EA, O'Connor R, et al. Induction of apoptosis by the Bcl-2 homolog Bak. Nature 1995; 374: 733-736.

39. Yang E, Zha J, Jockel J, Boise LH, Thompson CB, Korsmeyer SJ. Bad, a heterodimeric partner for Bcl-XL and Bcl-2, displaces Bax and promotes cell death. Cell 1995; 80: 285-291.

40. Takayama S, Sato T, Krajewski S, et al. Cloning and functional analysis of BAG-1: a novel Bcl-2 binding protein with anti-cell death activity. Cell 1995; 80: 279-284.

41. Sato T, Hanada M, Bodrug S, et al. Interactions among members of the Bcl-2 protein family analyzed with a two-yeast hybrid system. Proc Natl Acad Sci USA 1994; 91: 9238-9242.

42. Evans CA, Owen-Lynch PJ, Whetton AD, Dive C. Activation of the Abelson tyrosine kinase activity is associated with suppression of apoptosis in hemopoietic cells. Cancer Res 1993; 53: 1735-1738.

43. McGahon AR, Bissonnette R, Schmitt M, Cotter KM, Green DR, Cotter TG. BCR-ABL maintains resistance of chronic myelogenous leukemia cells to apoptotic cell death. Blood 1994; 83: 1179-1187.

44. Kagi D, Ledermann B, Bürki K, et al. Cytotoxicity mediated by T-cells and natural killer cells is greatly impaired in perforin-deficient mice. Nature 1994; 369: 31-37.

45. Ray CA, Black RA, Kronheim SR, et al. Viral inhibition of inflammation: cowpox virus encodes an inhibitor of the interleukin-1 $\beta$ converting enzyme. Cell 1992; 69: 597-604.

46. Enari M, Hug H, Nagata S. Involvement of an ICE-like protease in Fas-mediated apoptosis. Nature 1995; 375: 78-81.

47. Los M, Van de Craen M, Penning LC, et al. Requirement of an ICE/CED-3 protease for Fas/APO-1-mediated apoptosis. Nature 1995; 375: 81-83.

48. Rao L, Debbas M, Sabbatini P, Hockenbery D, Korsmeyer $\mathrm{S}$, White E. The adenovirus E1A proteins induce apoptosis which is inhibited by the E1B $19 \mathrm{~K}$ and Bcl-2 proteins. Proc Natl Acad Sci USA 1992; 89: 7742-7746. 
49. Henderson S, Huen D, Rowe M, Dawson C, Johnson G, Rickinson A. Epstein-Barr virus-coded BHRF1 protein, a viral homolog of $\mathrm{Bcl}-2$, protects human B-cells from programmed cell death. Proc Natl Acad Sci USA 1993; 90: 8479-8483.

50. Henderson S, Rowe M, Gregory C, et al. Induction of $b c l-2$ expression by Epstein-Barr virus latent membrane protein 1 protects B cells from programmed cell death. Cell 1991; 65: 1107-1115.

51. Roy N, Mahadevan MS, McLean M, et al. The gene for neuronal apoptosis inhibitory protein is partially deleted in individuals with spinal muscular atrophy. Cell 1995; 80: 167-178.

52. Mannick JB, Asano K, Izumi K, Kieff E, Stamler JS. Nitric oxide produced by human B-lymphocytes inhibits apoptosis and Epstein-Barr virus reactivation. Cell 1994; 79: $1137-1146$.

53. Emlen W, Niebur J, Kadera R. Accelerated in vitro apoptosis of lymphocytes from patients with systemic lupus erythematosus. J Immunol 1994; 152: 3685-3692.

54. Juntti-Berggren L, Larsson O, Rorsman $\mathrm{P}$, et al. Increased activity of L-type $\mathrm{Ca}^{2+}$ channels exposed to serum from patients with type I diabetes. Science 1993; 261: 86-90.

55. Garchon HJ, Luan JJ, Eloy L, Bedossa P, Bach JF. Genetic analysis of immune dysfunction in nonobese diabetic (NOD) mice: mapping of a susceptibility locus close to the Bcl-2 gene correlates with increased resistance of NOD T-cells to apoptosis induction. Eur J Immunol 1994; 24: 380-384.

56. Strasser A, Whittingham S, Vaux DL, et al. Enforced Bcl-2 expression in B-lymphoid cells prolongs antibody responses and elicits autoimmune disease. Proc Natl Acad Sci USA 1991; 88: 8661-8665.

57. Watanabe-Fukunaga R, Brannan CI, Copeland NG, Jenkins NA, Nagata S. Lymphoproliferation disorder in mice explained by defects in Fas antigen that mediates apoptosis. Nature 1992; 356: 314-317.

58. Roths JB, Murphy ED, Eicher EM. A new mutation, gld, that produces lymphoproliferation and autoimmunity in C3H/HeJ mice. J Exp Med 1984; 159: 1-20.

59. Nagata S, Goldstein P. The Fas death factor. Science 1995; 267: 1449-1456.

60. Suda T, Takahashi T, Goldstein P, Nagata S. Molecular cloning and expression of the Fas ligand, a novel member of the tumor necrosis factor family. Cell 1993; 75: $1169-1178$.

61. Itoh $\mathrm{N}$, Yonehara $\mathrm{S}$, Ishii $\mathrm{A}$, et al. The polypeptide encoded by the cDNA for human cell surface antigen Fas can mediate apoptosis. Cell 1991; 66: 233-243

62. Sato T, Irie S, Kitida S, Reed JC. FAP-1: a protein tyrosine phosphatase that associates with Fas. Science 1995; 168: 411-415.

63. Chinnaiyan AM, O'Rourke K, Tewari M, Dixit VML. FADD, a novel death domain-containing protein, interacts with the death domain of Fas and initiates apoptosis. Cell 1995; 81: 505-512.

64. Stanger BZ, Leder P, Lee TH, Kim E, Seed B. RIP: a novel protein containing a death domain that interacts with Fas/APO-1 (CD95) in yeast and causes cell death. Cell 1995; 81: 513-523.

65. Boldin MP, Varfolomeev EE, Pancer Z, Mett L, Camonis $\mathrm{JH}$, Wallach D. A novel protein that interacts with the death domain of Fas/APO1 contains a sequence motif related to death domain. J Biol Chem 1995; 270: 7795-7798.

66. Cifone MG, De Maria R, Roncaioli P, et al. Apoptotic signaling through CD95 (Fas/APO-1) activates an acidic sphingomyelinase. J Exp Med 1994; 180: 1547-1552.
67. Dhein J, Walczak H, Baümler C, Debatin KM, Krammer $\mathrm{PH}$. Autocrine T-cell suicide mediated by APO-1/(Fas/ CD95). Nature 1995; 373: 438-441.

68. Ju ST, Panka DJ, Cui H, et al. Fas(CD95)/FasL interactions required for programmed cell death after T-cell activation. Nature 1995; 373: 444-448.

69. Berke G. The CTL's kiss of death. Cell 1995; 81: 9-12.

70. Watson M, Roa JK, Gilkeson GS, et al. Genetic analysis of MRL-lpr mice: relationship of the Fas apoptosis gene to disease manifestations and renal disease-modifying loci. J Exp Med 1992; 176: 1645-1656.

71. Fischer GH, Rosenberg FJ, Straus SE, et al. Crosslinking CD4 by human immunodeficiency virus gp120 primes T-cells for activation-induced apoptosis. J Exp Med 1992; 176: 1099-1106.

72. Rieux-Laucat F, Le Deist F, Hivroz C, et al. Mutations in Fas associated with human lymphoproliferative syndrome and autoimmunity. Science 1995; 268: 13471349.

73. Lenardo MJ, Puck JM. Dominant interfering Fas gene mutations impair apoptosis in a human autoimmune lymphoproliferative syndrome. Cell 1995; 81: 935-936.

74. Cheng J, Zhou T, Liu C, et al. Protection from Fasmediated apoptosis by a soluble form of the Fas molecule. Science 1994; 263: 1759-1762.

75. Tanaka M, Suda T, Takahashi T, Nagata S. Expression of the functional soluble form of human Fas ligand in activated lymphocytes. EMBO J 1995; 14: 1129-1135.

76. Ogasawara J, Watanabe-Fukunaga $\mathrm{R}$, Adachi $\mathrm{M}$, et al. Lethal effect of the anti-Fas antibody in mice. Nature 1993; 364: 806-809.

77. Ando S, Hirabayashi Y, Kon K, Inagaki F, Tate S, Whittaker VP. A trisialoganglioside containing a sialyl alpha 2-6 N-acetylgalactosamine residue is a cholinergic-specific antigen, Chol-1 alpha. J Biochem 1992; 111: 287-290.

78. Ni R, Tomita Y, Matsuda K, et al. Fas-mediated apoptosis in primary cultured mouse hepatocytes. Exp Cell Res 1994; 215: 332-337.

79. Hiramatsu N, Hayashi N, Katayama K, et al. Immunohistochemical detection of Fas antigen in liver tissue of patients with chronic hepatitis C. Hepatology 1994; 19: 1354-1359.

80. Meyaard L, Otto SA, Keet IP, Roos MT, Miedema F. Programmed death of T-cells in human immunodeficiency virus infection: no correlation with progression to disease. J Clin Invest 1994; 93: 982-988.

81. Banda NK, Bernier J, Kurahara DK, et al. Crosslinking CD4 by human immunodeficiency virus gp120 primes T-cells for activation-induced apoptosis. J Exp Med 1992; 176: 1099-1106.

82. Westendorp MO, Frank R, Ochsenbauer C, et al. Sensitization of T-cells to CD95-mediated apoptosis by HIV-1 tat and gp120. Nature 1995; 375: 497-500.

83. Katsikis PD, Wunderlich ES, Smith CA, Herzenberg LA. Fas antigen stimulation induces marked apoptosis of Tlymphocytes in human immunodeficiency virus-infected individuals. J Exp Med 1995; 181: 2029-2036.

84. Leno M, Simpson RM, Bowers FS, Kindt TJ. Human T-lymphocyte virus 1 from a leukemogenic cell line mediates in vivo and in vitro lymphocyte apoptosis. J Exp Med 1995; 181: 1575-1580.

85. Cohen DA, Fitzpatrick EA, Barve SS, et al. Activation dependent apoptosis in CD4+ T-cells during murine AIDS. Cell Immunol 1993; 151: 392-402.

86. Nunez G, London L, Hockenbery D, Alexander M, McKearn JP, Korsmeyer SJ. Deregulated Bcl-2 gene 
expression selectively prolongs survival of growth factor-deprived hemopoietic cell lines. J Immunol 1990; 144: 3602-3610.

87. Yoshida Y. Hypothesis: apoptosis may be the mechanism responsible for the premature intramedullary cell death in the myelodysplastic syndrome. Leukemia 1993; 7: 144-146.

88. Clark DM, Lampert IA. Apoptosis is a common histopathological finding in myelodysplastic syndrome: the correlate of ineffective hemopoiesis. Leuk Lymphoma 1990; 2: 415-418.

89. Yuan J, Angelucci E, Lucarelli G, et al. Accelerated programmed cell death (apoptosis) in erythroid precursors of patients with severe $\beta$-thalassemia (Cooley's anemia). Blood 1993; 82: 374-377.

90. Choi DW. Excitotoxic cell death. J Neurobiol 1992; 23: 1261-1276.

91. Loo DT, Copani A, Pike CJ, Whittemore ER, Walencewicz AJ, Cotman CW. Apoptosis is induced by beta-amyloid in cultured central nervous system neurons. Proc Natl Acad Sci USA 1993; 90: 7951-7955.

92. Edwards SN, Buckmaster AE, Tolkovsky AM. The death program in cultured sympathetic neurones can be suppressed at the post-translational level by nerve growth factor, cyclic AMP, and depolarization. J Neurochem 1991; 57: 2140-2143.

93. Barres BA, Hart IK, Coles HSR, et al. Cell death and control of cell survival in the oligodendrocyte lineage. Cell 1992; 70: 31-46.

94. Arenas E, Persson H. Neurotrophin-3 prevents the death of adult central noradrenergic neurons in vivo. Nature 1994; 367: 368-371.

95. Rosen DR, Siddique T, Patterson D, et al. Mutations in $\mathrm{Cu} / \mathrm{Zn}$ superoxide dismutase gene are associated with familial amyotrophic lateral sclerosis. Nature 1993; 362: $59-62$.

96. Rao VR, Cohen GB, Oprian DD. Rhodopsin mutation G90D and a molecular mechanism for congenital nightblindness. Nature 1994; 367: 639-642.

97. Woo D. Apoptosis and loss of renal tissue in polycystic kidney diseases. New Engl J Med 1995; 333: 18-25.

98. Goldin RD, Hunt NC, Clark J, Wickramassinghe SN. Apoptotic bodies in a murine model of alcoholic liver disease: reversibility of ethanol-induced changes. J Pathol 1993; 171: 73-76.

99. Gottlieb RA, Burleson KO, Kloner RA, Babior BM, Engler RL. Reperfusion injury induces apoptosis in rabbit cardiomyocytes. J Clin Invest 1994; 94: 1621-1628.

100. Han DKM, Haudenschild CC, Hong MK, Tinkle BT, Leon MB, Liau G. Evidence for apoptosis in human atherogenesis and in rat vascular injury model. Am J Pathol 1995; 147: 267-277.

101. Geng YJ, Libby P. Evidence for apoptosis in advanced human atheroma: co-localization with interleukin- $1 \beta$ converting enzyme. Am J Pathol 1995; 147: 251-266.

102. Whyte MKB, Meagher LC, MacDermot J, Haslett C. Impairment of function in aging neutrophils is associated with apoptosis. J Immunol 1993; 150: 5124-5134.

103. Lockshin RA, Zackeri ZF. Programmed cell death: new thoughts and relevance to aging. J Gerontol 1990; 45: $135-140$.

104. Zhou T, Edwards CK 3rd, Mountz JD. Prevention of age-related T-cell apoptosis defect in CD2-Fas-transgenic mice. J Exp Med 1995; 182: 129-137.

105. Hodes RJ. Molecular alterations in the aging immune system. J Exp Med 1995; 182: 1-3.

106. Casciola-Rosen LA, Anhalt G, Rosen A. Autoantigens targeted in systemic lupus erythematosus are clustered in two populations of surface blebs on apoptotic keratinocytes. J Exp Med 1994; 179: 1317-1330.

107. Szende B, Romics I, Vass L. Apoptosis in prostate cancer after hormonal treatment. Lancet 1993; 342: 1422.

108. Levine EL, Davidson SE, Roberts SA, Chadwick CA, Potten CS, West CM. Apoptosis as predictor to radiotherapy in cervical carcinoma. Lancet 1994; 344: 472.

109. Walkinshaw $\mathrm{G}$, Waters CM. Induction of apoptosis in catecholaminergic PC12 cells by L-DOPA: implications for the treatment of Parkinson's disease. J Clin Invest 1995; 95: 2458-2464.

110. Bertrand R, Solary E, Jenkins J, Pommier Y. Apoptosis and its modulation in human promyelocytic HL-60 cells treated with topoisomerase I and II inhibitors. Exp Cell Res 1993; 207: 388-397.

111. Brown DG, Sun XM, Cohen GM. Dexamethasoneinduced apoptosis involves cleavage of DNA to large fragments prior to internucleosomal fragmentation. $J$ Biol Chem 1993; 268: 3037-3039.

112. Jacobson MD, Burne JF, Raff MC. Programmed cell death and Bcl-2 protection in the absence of a nucleus. EMBO J 1994; 13: 1899-1910.

113. Nakajima H, Goldstein P, Henkart PA. The target cell nucleus is not required for cell-mediated granzyme- or Fas-based cytotoxicity. J Exp Med 1995; 181: 1905-1909.

114. Bertrand B, Kohn KW, Solary E, Pommier Y. Detection of apoptosis-associated DNA fragmentation using a rapid and quantitative filter binding assay. Drug Dev Res 1995; 34: 138-144.

115. McGowan AJ, Fernandes RS, Verhaegen S, Cotter TG. Zinc inhibits UV radiation-induced apoptosis but fails to prevent subsequent cell death. Int J Rad Biol 1994; 66: 343-349.

116. Wang L, Miura M, Bergeron L, Zhu H, Yuan J. Ich-1, an ICE/ced-3-related gene, encodes both positive and negative regulators of programmed cell death. Cell 1994; 78: 739-750.

117. Alnemri ES, Fernandez-Alnemri T, Litwack G. Cloning and expression of four novel isoforms of human interleukin-1 beta converting enzyme with different apoptotic activities. J Biol Chem 1995; 270: 4312-4317.

118. Dubrez L, Goldwasser F, Genne P, Pommier Y, Solary E. The role of cell cycle regulation and apoptosis triggering in determining the sensitivity of leukemic cells to topoisomerase I and II inhibitors. Leukemia 1995; 9: 1013-1024.

119. Pommier Y, Leteurtre F, Fesen M, et al. Cellular determinants of sensitivity and resistance to DNA topoisomerase inhibitors. Cancer Invest 1994; 12: 530-542.

120. Kamesaki S, Kamesaki H, Jorgensen TJ, Tanizawa A, Pommier Y, Cossman J. Bcl-2 protein inhibits etoposide-induced apoptosis through its effects on events subsequent to topoisomerase II-induced DNA strand breaks ant their repair. Cancer Res 1993; 53: 4251.

121. Campos L, Rouault JP, Sabido O, et al. High expression of Bcl-2 protein in acute myeloblastic leukemia cells is associated with poor response to chemotherapy. Blood 1993; 81: 3091-3096.

122. Kondo S, Yin D, Takeuchi J, Morimura T, Oda Y, Kikuchi $\mathrm{H}$. bcl-2 gene enables rescue from in vitro myelosuppression (bone marrow cell death) induced by chemotherapy. Br J Cancer 1994; 70: 421-426.

123. Campos L, Sabido O, Rouault JP, Guyotat D. Effects of Bcl-2 antisense oligonucleotides on in vitro proliferation and survival of normal bone marrow progenitors and leukemic cells. Blood 1994; 84: 595-600. 
124. de Fabritiis P, Amadori S, Calabretta B, Mandelli F. Elimination of clonogenic Philadelphia positive cells using BCR-ABL antisense oligonucleotides. Bone Marrow Transpl 1993; 12: 261-265.

125. Veis DJ, Sorenson CM, Shutter JR, Korsmeyer SJ. Bcl2-deficient mice demonstrate fulminant lymphoid apoptosis, polycystic kidneys, and hypopigmented hair. Cell 1993; 75: 229-240.

126. Motoyama N, Wang F, Roth KA, et al. Massive cell death of immature hematopoietic cells and neurons in Bcl-x-deficient mice. Science 1995; 267: 1506-1510.

127. Levy Y, Brouet JC. Interleukin-10 prevents spontaneous death of germinal center B-cells by induction of the Bcl2 protein. J Clin Invest 1994; 93: 424-428.

128. Dancescu M, Rubio-Trujillo M, Biron G, Bron D, Delespesse G, Sarfati M. Interleukin-4 protects chronic lymphocytic leukemic B-cells from death by apoptosis and upregulates Bcl-2 expression. J Exp Med 1992; 176: 1319-1326.

129. Sarin A, Clerici M, Blatt SP, Hendrix CW, Shearer GM, Henkart PA. Inhibition of activation-induced programmed cell death and restoration of defective immune responses of HIV+ donors by cysteine protease inhibitors. $J$ Immunol 1994; 153: 862-872.

130. Squier MKT, Miller ACK, Malkinson AM, Cohen JJ. Calpain activation in apoptosis. J Cell Physiol 1994; 159: 229-237.

131. Wright SC, Wei QS, Zhong J, Zheng H, Kinder DH, Larrick JW. Purification of a $24 \mathrm{kD}$ protease from apoptotic tumor cells that activate DNA fragmentation. $J$ Exp Med 1994; 180: 2113-2123.

132. Irmler M, Hertig S, MacDonald HR, et al. Granzyme A is an interleukin-1 beta converting enzyme. $J$ Exp Med 1995; 181: 1917-1922.

133. Staal FJT, Anderson MT, Staal GEJ, Herzenberg LA, Gitler C, Herzenberg LA. Redox regulation of signal transduction: tyrosine phosphorylation and calcium influx. Proc Natl Acad Sci USA 1994; 91: 3169-3122.

134. Dröge W, Eck HP, Mihm S. HIV-induced cysteine deficiency and T-cell dysfunction: a rationale for treatment with N-acetylcysteine. Immunol Today 1992; 13: 211-214.

135. Fisher DE. Apoptosis in cancer therapy: crossing the threshold. Cell 1994; 78: 539-542.

136. Horio Y, Takahashi T, Kuroishi T, et al. Prognostic significance of $p 53$ deletions in primary resected non-small cell lung cancer. Cancer Res 1993; 53: 1-4.

137. Elrouby $\mathrm{S}$, Thomas $\mathrm{A}$, Costin $\mathrm{D}$, et al. p53 gene mutation in B-cell chronic lymphocytic leukemia is associated with drug resistance and is independent of $m d r l / m d r 3$ gene expression. Blood 1993; 82: 3452-3459.

138. Lowe SC, Bodis S, McClatchey, et al. P53 status and the efficacy of cancer therapy in vivo. Science 1994; 266: 807-810.

139. Critchfield JM, Racke MK, Zuniga-Pflücker JC, et al.
T-cell deletion in high antigen dose therapy of autoimmune encephalitis. Science 1994; 263: 1139-1143.

140. Pulendran B, Kannourakis G, Nouri S, Smith KGC, Nossal GJV. Soluble antigen can cause enhanced apoptosis of germinal-centre B-cells. Nature 1995; 375: 331-334.

141. Shokat KM, Goodnow CC. Antigen-induced B-cell death and elimination during germinal centre immune response. Nature 1995; 375: 334-338.

142. Deftos M, Olee T, Carson DA, Chen PP. Defining the genetic origins of three rheumatoid synovium-derived IgG rheumatoid factors. J Clin Invest 1994; 93: 25252553.

143. Nicolle NW, Nag B, Sharma SD, et al. Specific tolerance to an acetylcholine receptor epitope induced in vitro in myasthenia gravis $\mathrm{CD} 4+$ lymphocytes by soluble major histocompatibility complex class II-peptide complexes. J Clin Invest 1994; 93: 1361-1369.

144. Kobayashi N, Hamamoto Y, Yamùamoto N, Ishii A, Yonehara M, Yonehara S. Anti-Fas monoclonal antibody is cytocidal to human immunodeficiency virusinfected cells without augmenting viral replication. Proc Natl Acad Sci USA 1990; 87: 9620-9624.

145. Debatin KM, Goldman CK, Waldmann TA, Krammer PH. APO-1 induced apoptosis of leukemia cells from patients with adult T-cell leukemia. Blood 1993; 81: 2972-2977.

146. Morimoto H, Yonehara S, Bonavida B. Overcoming tumor necrosis factor and drug resistance of human tumor cell lines by combination treatment with anti-Fas antibody and drugs or toxins. Cancer Res 1993; 53: 2591-2596.

147. Neta R, Stiefel SM, Finkelman F, Herrmann S, Ali N. IL-12 protects bone marrow from and sensitizes intestinal tract to ionizing radiations. J Immunol 1994; 153: 4230-4237.

148. Löwenberg B, Touw P. Hematopoietic growth factors and their receptors in acute leukemia. Blood 1993; 81: 281-292.

149. Lotem J, Sachs L. Hematopoietic cytokines inhibit apoptosis induced by transforming growth factor- $\beta$ and cancer chemotherapy compounds in myeloid leukemic cells. Blood 1992; 80: 1750-1757.

150. Estey E, Thall PF, Kantarjian H, et al. Treatment of newly diagnosed acute myelognous leukemia with granulocyte-macrophage colony-stimulating factor (GM-CSF) before and during continuous-infusion high dose ara-C + daunorubicin: comparison to patients treated without GM-CSF. Blood 1992; 79: 2246-2255.

151. Colombel M, Olsson CA. Hormone-regulated apoptosis results from re-entry of differentiated prostate cells onto a defective cell cycle. Cancer Res 1992; 52: 4313-4319.

152. Lunardi-Iskandar Y, Bryant JL, Zeman RA, et al. Tumorigenesis and metastasis of neoplastic Kaposi's sarcoma cell line in immunodeficient mice blocked by a human pregnancy hormone. Nature 1995; 375: 64-68. 